\title{
Effect of Quinacridone Pigments on Properties and Morphology of Injection Molded Isotactic Polypropylene
}

\author{
Mateusz Barczewski, ${ }^{1}$ Danuta Matykiewicz, ${ }^{1}$ and Bartłomiej Hoffmann ${ }^{2}$ \\ ${ }^{1}$ Polymer Processing Division, Institute of Materials Technology, Poznań University of Technology, Piotrowo 3, \\ 61-138 Poznań, Poland \\ ${ }^{2}$ R\&D Project Office Laboratory, Hempel A/S, Lundtoftegårdsvej 91, 2800 Kgs. Lyngby, Denmark
}

Correspondence should be addressed to Mateusz Barczewski; mateusz.barczewski@put.poznan.pl

Received 15 December 2016; Accepted 14 February 2017; Published 16 March 2017

Academic Editor: Marta Fernández-García

\begin{abstract}
Copyright ( 2017 Mateusz Barczewski et al. This is an open access article distributed under the Creative Commons Attribution License, which permits unrestricted use, distribution, and reproduction in any medium, provided the original work is properly cited.

Two quinacridone pigments were added $(0.01 ; 0.05 ; 0.1 ; 0.5 ; 1 ; 2 \mathrm{wt} \%)$ to isotactic polypropylene (iPP), and their influence on mechanical and thermomechanical properties were investigated. Complex mechanical and thermomechanical iPP properties analyses, including static tensile test, Dynstat impact resistance measurement, and hardness test, as well as dynamic mechanic thermal analysis (DMTA), were realized in reference to morphological changes of polymeric materials. In order to understand the differences in modification efficiency and changes in polymorphism of polypropylene matrix caused by incorporation of pigments, differential scanning calorimetry (DSC) and wide-angle X-ray scattering (WAXS) experiments were done. Both pigments acted as highly effective nucleating agents that influence morphology and mechanical properties of isotactic polypropylene injection molded samples. Differences between polypropylene samples nucleated by two pigments may be attributed to different heterogeneous nucleation behavior dependent on pigment type. As it was proved by WAXS investigations, the addition of $\gamma$-quinacridone (E5B) led to crystallization of polypropylene in hexagonal phase ( $\beta$-iPP), while for $\beta$-quinacridone (ER 02) modified polypropylene no evidence of iPP $\beta$-phase was observed.
\end{abstract}

\section{Introduction}

Due to the nature of thermoplastic polymers, incorporation of additives, such as pigments or fillers, results in changes in polymeric matrix properties and structure. The influence of additives on polymeric material morphology is significant, especially for semicrystalline polymers. Isotactic polypropylene (iPP) is a typical commercially used structural polymer, often applied in injection molding processing and susceptible to heterogeneous nucleation [1-11]. iPP can crystallize into different crystalline structures, such as $\alpha$ (monoclinic), $\beta$ (hexagonal), or $\gamma$ (orthorhombic), depending on microstructural features and crystallization conditions as well as use of specially designed nucleating agents (NAs) $[1,7,12-17]$. Most of the additives may act as nucleating agents and lead to heterogeneous nucleation effect which in turn causes changes in polymer structure. They are additives which provide additional nuclei that accelerate crystallization process and promote nucleation together with crystal growth $[7,8]$. High efficiency of nucleating agents allows adding even very little amounts of NAs to polymer matrix to obtain specified properties of the modified semicrystalline polymer [9-11]. Dyes and pigments also act as highly effective modifiers and nucleating agents [18]. The latest studies focus on describing pigments which promote $\beta$-nucleation of isotactic polypropylene, such as $\gamma$-quinacridone E3B, Indigosol Grey IBL, Cibantine Orange HR, Indigosol Golden Yellow IGK, and Cibantine Blue 2B [19-22]. What should be noticed is that most polymer additives incorporated into polymeric matrix to change their color are also $\alpha$-nucleating agents. Quinacridone, namely, the 5,12-dihydroquino[2,3b]acridine-7,14-dione $\left(\mathrm{C}_{20} \mathrm{H}_{12} \mathrm{~N}_{2} \mathrm{O}_{2}\right)$, is the pigment most frequently used for creating red-violet shades. Both high photo and thermal stability effect their wide application 
range in automotive finishes, paints, high grade printing, and plastics $[23,24]$. Regardless of the crystallographic form of the pigments, different red shades may be obtained. Two most stable quinacridone phases, $\beta$ and $\gamma$, result in reddish violet and red colors, respectively. Specific surface of quinacridone pigment, insoluble in polypropylene melt, allows for the epitaxial growth of polymer crystals. Different crystallographic forms of the pigment led to formulation of different polypropylene crystallization behaviors [25]. Even the slightest changes in their chemical structure resulted in significant variations in coloring efficiency, while, in case of polymer colorization, morphological and property modification of the injection molded products occurred. The aim of our studies was to assess the influence of two different commercial quinacridone pigments $(\beta$ - and $\gamma$ phase) on the mechanical and thermal properties as well as structure of isotactic polypropylene. Complex evaluation of the properties' changes and their influence on the functional quality of injection molded parts was discussed in reference to pigmentation efficiency of both quinacridone-based pigments.

\section{Experimental}

2.1. Materials and Sample Preparation. Commercial isotactic polypropylene Moplen HP500J with $\mathrm{MFR}=3.2 \mathrm{~g} / 10 \mathrm{~min}$ $\left(230^{\circ}\right.$ C. $\left.2.16 \mathrm{~kg}\right)$ from Basell Orlen Polyolefins (Poland) was modified with two quinacridone pigments: Hostaperm RedViolet ER 02 ( $\beta$-quinacridone) and Hostaprem Red E5B 02 ( $\gamma$-quinacridone) delivered by Clariant (Switzerland).

Both pigments were incorporated into polymer matrix in various amounts $(0.01 ; 0.05 ; 0.1 ; 0.5 ; 1 ; 2 \mathrm{wt} \%)$. Before mixing in a molten state iPP pellets were milled into powder in a Tria high-speed grinder. Then, iPP and pigment powders were premixed using a high-speed rotary mixer Retsch GM200 $(t=3 \mathrm{~min}, n=3000 \mathrm{rpm})$. Next, all blends were mixed in a molten state using a Zamak 16/40 EHD twin screw extruder operated at $190^{\circ} \mathrm{C}$ and $100 \mathrm{rpm}$ and pelletized after cooling in a water bath. The specimens were prepared with an Engel ES 80/20 HLS injection molding machine. Injection molding process was realized with the following parameters: mold temperature $T_{\text {mould }}=40^{\circ} \mathrm{C}$, injection speed $V=100 \mathrm{~mm} / \mathrm{s}$, forming pressure $P_{f}=5.5 \mathrm{MPa}$, and cooling time $t=30 \mathrm{~s}$ [26].

2.2. Methods. Differential scanning calorimetry (DSC) measurements were performed using a Netzsch DSC 204 F1 Phoenix ${ }^{\circledR}$ apparatus with aluminum crucibles and approximately $5 \mathrm{mg}$ samples, under nitrogen flow. All the samples were heated up to $230^{\circ} \mathrm{C}$ and held in a molten state for $5 \mathrm{~min}$, followed by cooling down to $20^{\circ} \mathrm{C}$. Heating and cooling rates were equal to $10^{\circ} \mathrm{C} / \mathrm{min}$. This procedure was conducted twice to evaluate the DSC curves from the second melting procedure and gain broad information about iPP matrix modification [26].

Wide-angle X-ray diffraction (WAXS) measurements were carried out by using a Bruker D2 PHASER apparatus with XFlash ${ }^{\circledR}$. A monochromatic X-ray radiation with a wavelength of $\lambda=1.5406 \AA\left(\mathrm{Cu}_{\mathrm{K} \alpha}\right)$ was used. Identification was based on a reflected X-ray peak intensity analysis at a defined $2 \theta$ angle. The following crystallographic planes for monoclinic phase of iPP were analyzed, (110), (040), and (130), and correspond to diffraction angles 14.1, 16.9, and 18.8. For the hexagonal phase crystallographic plane (300) intensities at 16.2 diffraction angle were studied. In order to obtain information about $\beta$ amount in crystalline polypropylene matrix, Turner-Jones equation was used [27]:

$$
k=\frac{I_{\beta(300)}}{I_{\alpha 1(110)}+I_{\alpha 2(040)}+I_{\alpha 3(130)}+I_{\beta(300)}} \times 100 \%,
$$

where $k$ value is estimated percentage content of hexagonal phase in crystalline polypropylene matrix, $I_{\beta(300)}$ is the intensity of the diffraction peak measured for (300) crystallographic plane, and $I_{\alpha 1(110)}, I_{\alpha 2(040)}$, and $I_{\alpha 3(130)}$ are the intensities of the diffraction peaks measured at (110), (040), and (130) planes, respectively [26-30]. Evaluations were conducted in accordance with two-phase concept, in order to separate the crystalline fraction from the amorphous halo.

Tensile testing was used to study the elastic modulus, elongation at break, and yield strength. The tensile tests were performed as per ISO 527 with a Zwick/Roell Z020 tensile tester model 5101 at room temperature. The elastic modulus measurements were conducted at a crosshead speed of $1 \mathrm{~mm} / \mathrm{min}$, while the elongation at break was carried out at $50 \mathrm{~mm} / \mathrm{min}$.

The impact strengths of the unnotched samples with $10 \times$ $4 \times 15 \mathrm{~mm}$ dimensions were measured by the Dynstat method (DIN 53453).

Dynamic mechanical thermal analysis (DMTA) test was performed using the Anton Paar MCR 301 rheometer equipped with a torsion DMTA measuring tool. Investigations were carried out with a constant frequency of $1 \mathrm{~Hz}$ and a strain of $0.01 \%$. All samples were cooled down to $-40^{\circ} \mathrm{C}$ and heated up to $110^{\circ} \mathrm{C}$ with a temperature ramp of $2^{\circ} \mathrm{C} / \mathrm{min}$.

The color of pure and modified iPP injection molded samples was evaluated according to the Commission Internationale de l'Eclairage (CIE) through $L^{*} a^{*} b^{*}$ coordinates [31]. In this system, $L^{*}$ is the color lightness $\left(L^{*}=0\right.$ for black and $L^{*}=100$ for white), $a^{*}$ is the green $(-) / \operatorname{red}(+)$ axis, and $b^{*}$ is the blue $(-) /$ yellow $(+)$ axis. Color was determined by optical spectroscopy using X-rite SP60 spectrophotometer. The total color difference parameter $\left(\Delta E^{*}\right)$ was calculated according to following formulation [32]:

$$
\Delta E^{*}=\left[\left(\Delta L^{*}\right)^{2}+\left(\Delta a^{*}\right)^{2}+\left(\Delta b^{*}\right)^{2}\right]^{0.5} .
$$

\section{Results and Discussion}

3.1. Differential Scanning Calorimetry (DSC). The results of DSC investigations are presented in Table 1 . The influence of the incorporation of quinacridone pigments on melting temperature $\left(T_{M}\right)$, crystallization temperature $\left(T_{C}\right)$, and heat of fusion $\left(\Delta H_{m}\right)$ in a function of pigment amount was studied. It can be clearly observed that both pigments act as a highly effective nucleating agent. Isotactic polypropylene modified with both quinacridones revealed significant increase of $T_{C}$ 


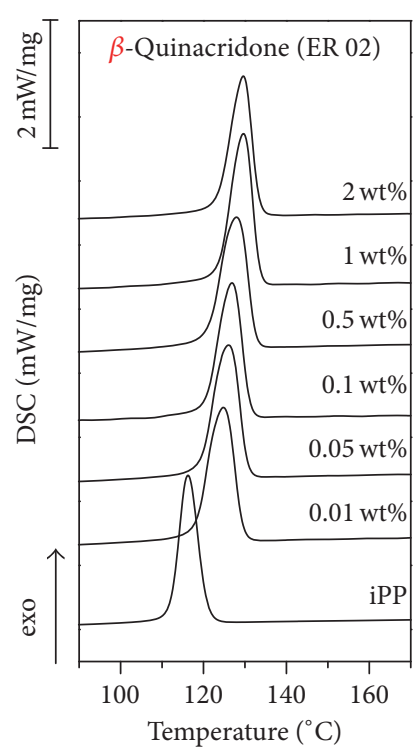

(a)

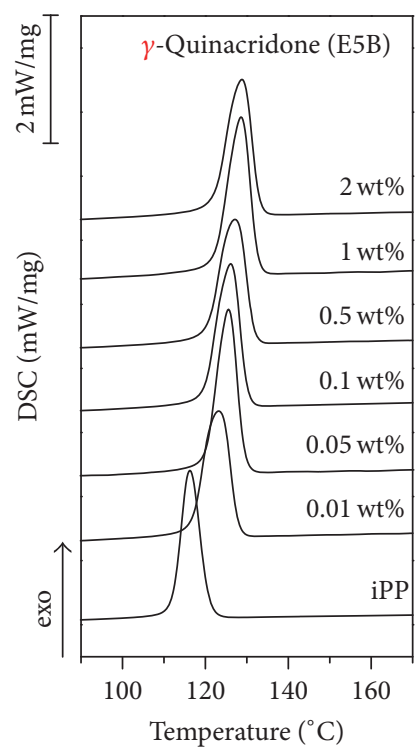

(b)

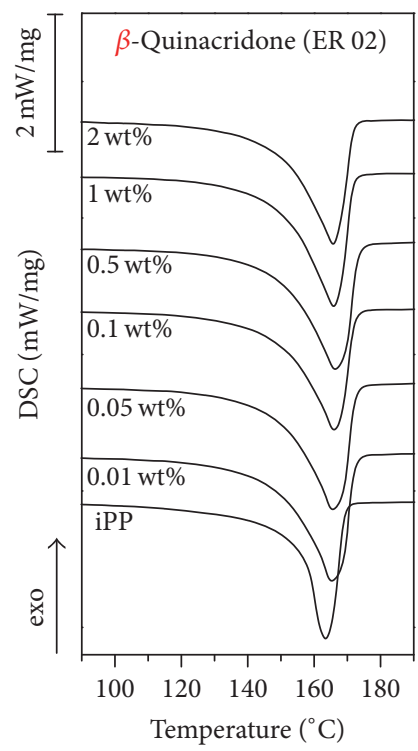

(c)

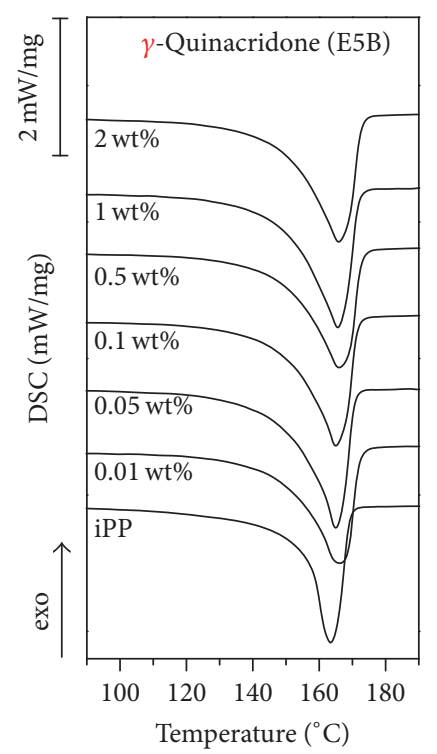

(d)

FIGURE 1: DSC cooling $(\mathrm{a}, \mathrm{b})$ and melting $(\mathrm{c}, \mathrm{d})$ curves for pure and modified iPP.

TABLE 1: Crystallization and melting parameters obtained from DSC for isotactic polypropylene with quinacridone pigments.

\begin{tabular}{|c|c|c|c|}
\hline Sample & $T_{M}$ & $T_{C}$ & $\begin{array}{c}\Delta H_{m} \\
(\mathrm{~J} / \mathrm{g})\end{array}$ \\
\hline Polypropylene (iPP) & 163.4 & 116.3 & 101.7 \\
\hline \multicolumn{4}{|c|}{ iPP $\beta$-quinacridone (ER 02) } \\
\hline $0.01 \mathrm{wt} \%$ & 165.3 & 124.8 & 117.9 \\
\hline $0.05 \mathrm{wt} \%$ & 165.7 & 126.0 & 117.7 \\
\hline $0.1 \mathrm{wt} \%$ & 165.5 & 127.2 & 104.7 \\
\hline $0.5 \mathrm{wt} \%$ & 166.3 & 127.9 & 120.3 \\
\hline $1 \mathrm{wt} \%$ & 165.8 & 129.7 & 108.0 \\
\hline $2 \mathrm{wt} \%$ & 165.7 & 129.6 & 103.3 \\
\hline \multicolumn{4}{|c|}{ iPP $\gamma$-quinacridone (E5B) } \\
\hline $0.01 \mathrm{wt} \%$ & 166.2 & 123.3 & 108.4 \\
\hline 0.05 wt $\%$ & 164.9 & 125.6 & 110.1 \\
\hline $0.1 \mathrm{wt} \%$ & 164.9 & 126.1 & 116.1 \\
\hline $0.5 \mathrm{wt} \%$ & 165.9 & 127.1 & 112.5 \\
\hline $1 \mathrm{wt} \%$ & 165.6 & 128.6 & 121.7 \\
\hline $2 \mathrm{wt} \%$ & 166.0 & 128.8 & 119.4 \\
\hline
\end{tabular}

values, even at the lowest amount of pigment $(0.01 \mathrm{wt} \%)$. Similar tendency was observed for both pigments. The lowest amount of the additive led to a strong increase of $T_{C}$, and subsequently the increase of pigment amount (more than $0.1 \mathrm{wt} \%$ ) was accompanied with a gradual small increase of $T_{C}$. Therefore, if one of the quinacridone pigments is used exclusively as a nucleating agent, it led to a decrease of the cooling time during injection molding. Moreover, the lowest amount of the additive results in the increase of polymer processability.

The highest increase of melting enthalpy, for iPP modified by $\beta$-quinacridone $(0.5 \mathrm{wt} \%)$, was observed, and for $\gamma$ quinacridone highest value of $\Delta H_{m}$ was noticed for iPP modified by 1 wt $\%$ of this additive. For all modified samples, melting enthalpy was improved in comparison to pure iPP; this fact may be related to nucleation ability of the pigments and improved crystallinity level of colored materials. Melting temperature of modified samples was only slightly higher in comparison to pure polypropylene, and the noted $3^{\circ} \mathrm{C}$ $T_{M}$ increase was independent of the pigment amount. It is noteworthy that, in the course of sample melting, the second peak, at $155^{\circ} \mathrm{C}$, indicating crystallization of the hexagonal form of iPP, was not observed. The DSC traces recorded during second heating and cooling of pure iPP and iPP modified by both quinacridone pigments were presented in Figure 1. 


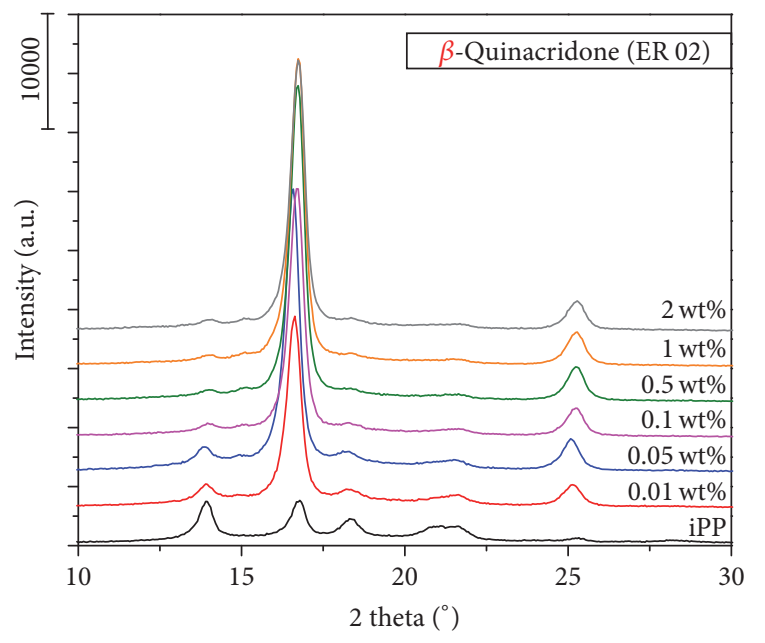

FIgURE 2: WAXS diffractograms for iPP and iPP modified with $\beta$ quinacridone (ER 02).

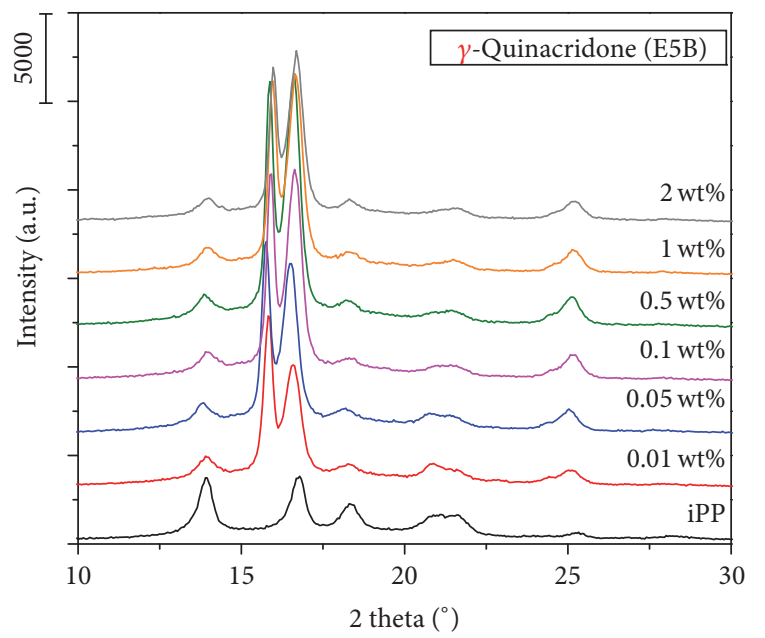

FIGURE 3: WAXS diffractograms for iPP and iPP modified with $\gamma$ quinacridone (E5B).

3.2. Wide-Angle X-Ray Scattering (WAXS). Diffractograms made for isotactic polypropylene modified with different amounts of $\beta$ - and $\gamma$-quinacridone were presented in Figures 2 and 3. On the basis of the WAXS investigations, strong dependence of the pigment crystallographic form on the polymorphism of the isotactic polypropylene was observed. $\beta$-Quinacridone (ER-02), as it was shown by DSC study, acted as a strong nucleating agent and promoted crystallization of iPP in monoclinic $\alpha$-phase. The incorporation of the smallest amount of $\beta$-quinacridone led to a strong peak intensity increase, at 2 theta angle $16.9^{\circ}$, which corresponded to (040) crystallographic plane. No evidence of the polypropylene $\beta$-phase, usually observed at $16.2^{\circ}$, was noted. For iPP modified with $\gamma$-quinacridone (E5B), a different tendency was observed. Diffractograms depicted in Figure 3 showed distinct diffraction peak at $16.2^{\circ}$ which corresponded to (300) iPP crystallographic plane and it was an evidence
TABLE 2: Content of $\beta$-phase in iPP samples nucleated by $\gamma$ quinacridone on the basis of WAXS data.

\begin{tabular}{lc}
\hline $\begin{array}{l}\gamma \text {-Quinacridone amount } \\
{[\text { wt } \%]}\end{array}$ & $\begin{array}{c}\text { Content of } \beta \text { phase in iPP } \\
{[\%]}\end{array}$ \\
\hline 0 & 0 \\
0.01 & 54.1 \\
0.05 & 49.3 \\
0.1 & 46.5 \\
0.5 & 46.8 \\
1 & 46.3 \\
2 & 43.0 \\
\hline
\end{tabular}

of hexagonal $\beta$-phase crystallization of the polypropylene matrix. In comparison to the examples of the iPP modification by E3B quinacridone pigment, described in literature, a lower efficiency of the $\beta$ nucleation caused by E5B was observed [19]. The peak at $16.2^{\circ}$ angle was not dominant for all samples, as usually observed for highly efficient $\beta$-nucleating agents [29]. The low amount of $\beta$-phase detected by WAXS measurements may be attributed to the absence of the second peak at the DSC melting curves.

The additional data presenting content of the $\beta$-phase in the polypropylene matrix as $k$-value, calculated in accordance with Turner-Jones equation, was presented in Table 2. What is interesting is that the highest $\beta$-nucleation efficiency was observed for the sample containing the lowest amount of the modifier $(0.01 \mathrm{wt} \%)$. The increasing amount of the $\gamma$ quinacridone pigment led to gradual decrease of the iPP $\beta$-phase amount. The $k$-value for iPP modified with $\beta$ quinacridone was not presented, due to negligible amount of the iPP beta-phase.

3.3. Mechanical Properties. The influence of quinacridone pigments on mechanical properties of isotactic polypropylene was assessed by means of static tensile test, as well as Dynstat impact test measurements. Tensile strength $\left(R_{m}\right)$, Young modulus $(E)$, elongation at break $(\varepsilon)$, and impact strength $(a)$ mean values are listed in Table 3 . The incorporation of both pigments resulted in similar changes in mechanical behavior of the samples. The samples modified by $\beta$-quinacridone revealed slightly higher elastic modulus than those containing $\gamma$-quinacridone; however, the registered values were similar in comparison to pure iPP. Higher stiffness of iPP modified by $\beta$-quinacridone also resulted in higher values of tensile strength. The incorporation of both pigments resulted in graduate decrease of elongation at break recorded during tensile experiment. Due to increasing $\alpha$-phase crystal domains caused by the presence of the pigments, elongation at break was reduced inversely proportionally to brittleness of the samples [33]. The higher the amount of pigment is, the lower the values of $\varepsilon$ were observed, with the exception of iPP samples modified with $\gamma$-quinacridone, which revealed lower values of elongation at break than those containing $\beta$ quinacridone. These results may be compared with impact strength values measured for iPP samples. The increasing 
TABLE 3: Mechanical properties of isotactic polypropylene modified with quinacridone pigments.

\begin{tabular}{|c|c|c|c|c|}
\hline Sample & $\begin{array}{l}\text { Tensile strength } \\
\text { (MPa) }\end{array}$ & $\begin{array}{l}\text { Young modulus } \\
\text { (MPa) }\end{array}$ & $\begin{array}{c}\text { Elongation at break } \\
(\%)\end{array}$ & $\begin{array}{c}\text { Impact strength } \\
\left(\mathrm{kJ} / \mathrm{m}^{2}\right)\end{array}$ \\
\hline Polypropylene (iPP) & $29.6 \pm 0.3$ & $1144 \pm 38$ & $359 \pm 83$ & $42.9 \pm 4.7$ \\
\hline \multicolumn{5}{|c|}{ iPP $\beta$-quinacridone (ER 02) } \\
\hline $0.01 \mathrm{wt} \%$ & $32.2 \pm 0.4$ & $1332 \pm 40$ & $199 \pm 30$ & $39.7 \pm 6.3$ \\
\hline 0.05 wt $\%$ & $33.1 \pm 0.3$ & $1423 \pm 49$ & $175 \pm 33$ & $43.1 \pm 2.5$ \\
\hline $0.1 \mathrm{wt} \%$ & $33.4 \pm 0.2$ & $1376 \pm 44$ & $155 \pm 40$ & $31.2 \pm 7.8$ \\
\hline $0.5 \mathrm{wt} \%$ & $34.1 \pm 0.1$ & $1421 \pm 39$ & $113 \pm 41$ & $28.3 \pm 3.2$ \\
\hline $1 \mathrm{wt} \%$ & $34.2 \pm 0.2$ & $1411 \pm 32$ & $83 \pm 24$ & $24.5 \pm 2.5$ \\
\hline $2 \mathrm{wt} \%$ & $33.6 \pm 0.2$ & $1378 \pm 18$ & $44 \pm 7$ & $15.9 \pm 4.5$ \\
\hline \multicolumn{5}{|c|}{ iPP $\gamma$-quinacridone (E5B) } \\
\hline $0.01 \mathrm{wt} \%$ & $31.5 \pm 0.6$ & $1284 \pm 82$ & $197 \pm 61$ & $45.5 \pm 4.8$ \\
\hline 0.05 wt $\%$ & $32.1 \pm 0.2$ & $1308 \pm 73$ & $164 \pm 42$ & $37.8 \pm 7.9$ \\
\hline $0.1 \mathrm{wt} \%$ & $32.3 \pm 0.2$ & $1317 \pm 66$ & $144 \pm 36$ & $38.4 \pm 4.7$ \\
\hline $0.5 w t \%$ & $33.1 \pm 0.2$ & $1373 \pm 83$ & $99 \pm 24$ & $24 \pm 2.5$ \\
\hline $1 \mathrm{wt} \%$ & $33.1 \pm 0.3$ & $1357 \pm 104$ & $49 \pm 25$ & $20.7 \pm 3.2$ \\
\hline $2 \mathrm{wt} \%$ & $32.9 \pm 0.2$ & $1364 \pm 68$ & $26 \pm 5$ & $16.6 \pm 1.1$ \\
\hline
\end{tabular}

content of both pigments caused a significant reduction of the polymeric material resistance to dynamic impact. Only in case of the sample containing the lowest amount of $\gamma$ quinacridone $(0.01 \mathrm{wt} \%)$, the impact strength increased in comparison to unmodified polypropylene. The increasing content of the pigments resulted in a significant reduction of impact strength with more than $50 \%$ reduction of this value observed for the highest amount of the additive. This result is in good agreement with the data presented by Sterzyński et al., as well as with the morphological analysis presented further herein [19].

The presented mechanical test results are in good agreement with WAXS data. The iPP modified with $\beta$ quinacridone, which acted as a strong iPP $\alpha$-nucleating agent, showed higher elastic modulus and tensile strength values in comparison to samples pigmented with $\gamma$-quinacridone. The highest impact resistance was denoted for the samples containing $0.01 \mathrm{wt} \%$ of $\mathrm{E} 5 \mathrm{~B}$, that is, the material with the highest content of iPP hexagonal phase. Therefore, whenever the main reason for the incorporation of quinacridone is $\beta$ nucleation of iPP, the amount of E5B pigment should always be the lowest possible. To conclude, $\beta$ nucleation efficiency of $\gamma$-quinacridones was the highest for low amounts of the additive (i.e., 0.001 to $0.01 \mathrm{wt} \%$ ); thus, those samples reveal high impact resistance with increased tensile strength and higher stiffness [19].

3.4. Dynamic Mechanical Thermal Analysis. Figure 4 illustrates the influence of quinacridone pigments addition on thermomechanical properties evaluated by DMTA. In Figures 4(a) and 4(b), the values of the storage modulus are depicted as a function of temperature. In both cases, the incorporation of pigments resulted in an increase of $G^{\prime}$ in the entire range of temperature measurement $(-40$ to $110^{\circ} \mathrm{C}$ ). On the other hand, $\beta$-quinacridone (ER-01), which was previously defined as a highly efficient nucleating agent promoting crystallization of the iPP in monoclinic phase, led to higher increase of the $G^{\prime}$ values, especially in lower temperatures, than $\gamma$-quinacridone (E5B). The above are in good agreement with DSC data. Samples revealing the highest melting enthalpy so also crystallinity level, mainly iPP containing $0.5 \mathrm{wt} \%$ of E5B and $1 \mathrm{wt} \%$ of the ER-01, exhibited the highest values of $G^{\prime}$. In Figures $4(\mathrm{c})$ and $4(\mathrm{~d})$, the variations of the $\tan \delta$ were presented as a function of the temperature and pigment amount. Two iPP transitions can be observed on the basis of the $\tan \delta$ analysis in the temperature measurement range. $\alpha$ transition at about $80^{\circ} \mathrm{C}$, corresponding to polymer rearrangements, which originate from the diffusion of the conformational defects in the crystalline phase to the crystalline-amorphous interphase, was observed. As both phases (amorphous and crystalline) are influenced by this transition, the analysis of the latter may be useful in gaining information about changes in the nucleated iPP structure [34]. Moreover, this transition, corresponding to softening point temperature, determines the end of the temperature usability range for the parts made of thermoplastic polymers. $\beta$-Transition of the iPP, corresponding to the glass transition temperature of iPP, is usually estimated on the basis of local maximum of the $\tan \delta$ (near $0^{\circ} \mathrm{C}$ ) and is connected with the amorphous parts of the iPP. It can be observed that the incorporation of pigments does not affect glass transition temperature of a modified iPP. All temperatures recorded at peak of $\tan \delta(T)$ oscillated near $14^{\circ} \mathrm{C}$. The differences between samples containing different amounts of quinacridones were negligible. There is an implication that the higher the value of $\tan \delta$ of a material, the bigger the ability to dissipate mechanical vibrations. It was observed that pure iPP revealed higher $\tan \delta$ than nucleated samples at room and higher temperatures. Considerable differences between iPP and colored samples were observed at various temperature values, dependent on the quinacridone grade. For iPP nucleated with $\gamma$-quinacridone, promotion of 


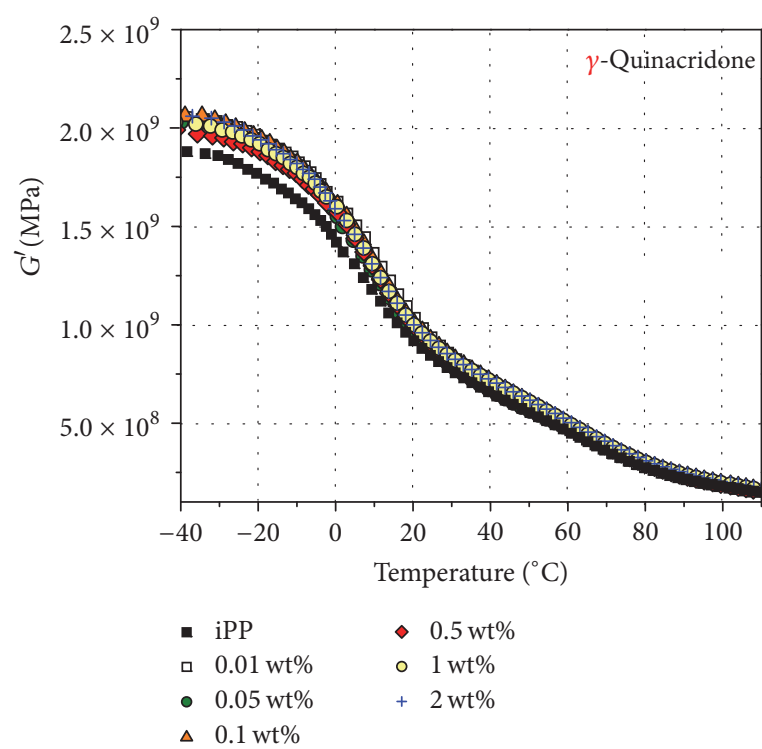

(a)

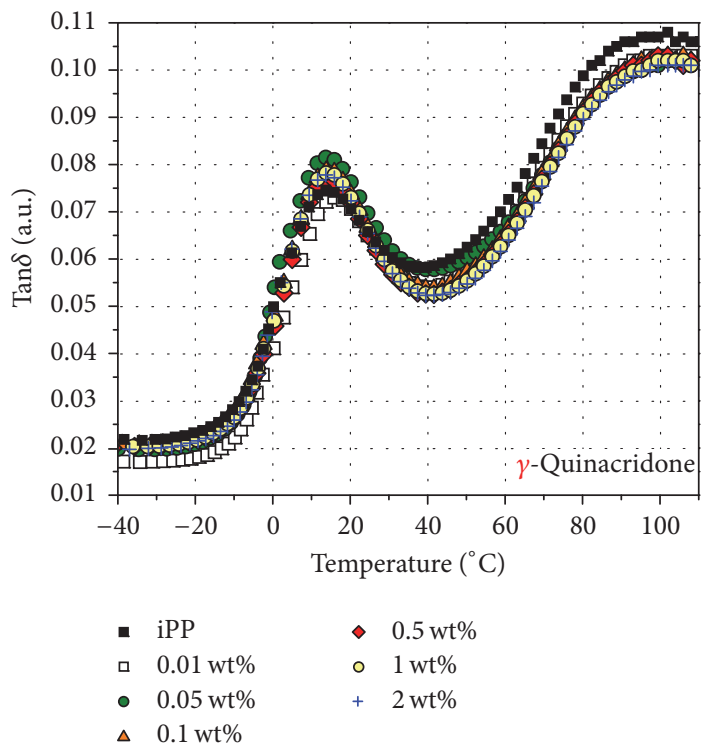

(c)

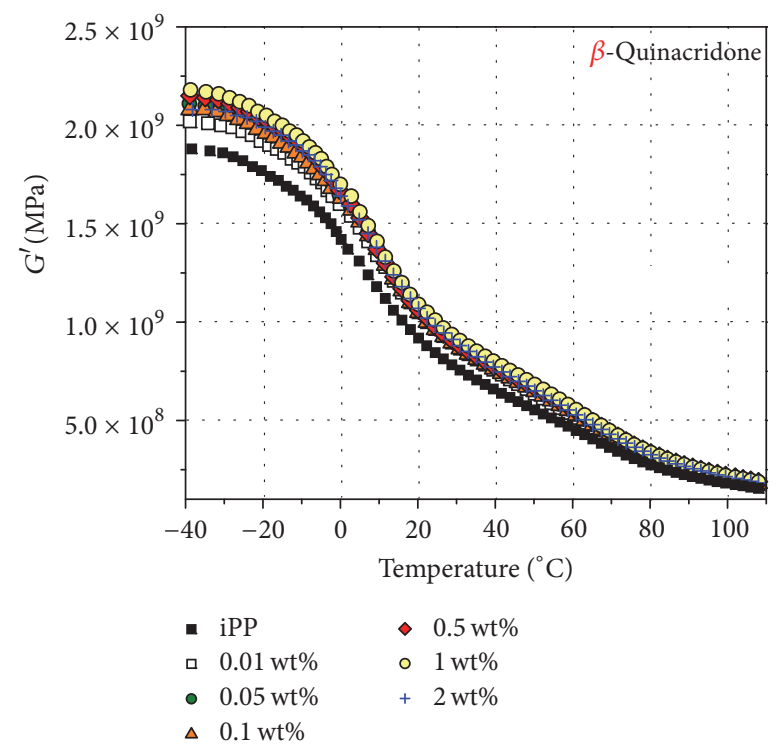

(b)

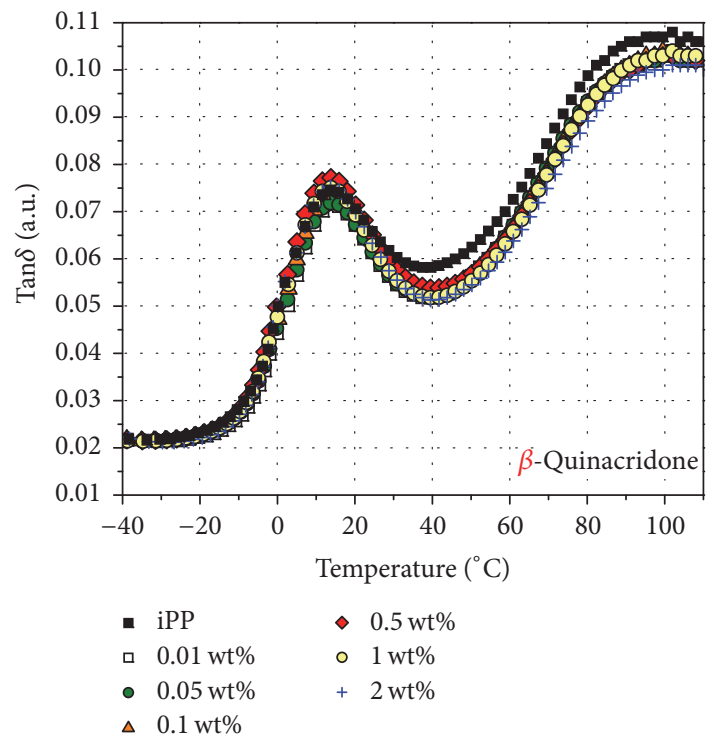

(d)

Figure 4: Storage modulus versus temperature $(\mathrm{a}, \mathrm{b})$ and $\tan \delta$ versus temperature $(\mathrm{c}, \mathrm{d})$ DMTA curves of iPP modified with $\gamma$-/ $\beta$ quinacridone.

polymeric matrix $\beta$-crystallization in the crossover point of $\tan \delta(T)$ was measured at $39.8^{\circ} \mathrm{C}$, while for $\beta$-quinacridone, the crossover temperature was $23^{\circ} \mathrm{C}$. This phenomenon may be attributed to the presence of ductile $\beta$-iPP phase which leads to higher dissipative behavior in room temperatures. Both pigments also cause a strong increase of the softening point temperature, which may be read from $\tan \delta$ iPP $\alpha$ transition. The influence of the quinacridone pigments is comparable for both nucleating systems. The softening temperature evaluated on the basis of DMTA increased from 96.5 to $102^{\circ} \mathrm{C}$. Lower values of $\tan \delta$ at $\alpha$-transition may be attributed to higher amount of crystalline phase and higher stiffness of the colored samples.
3.5. Color Evaluation. Photographs of injection molded samples containing various amounts of $\beta$ - and $\gamma$-quinacridone pigments are presented in Figure 5. Parametrized changes of the sample color measured in $L^{*}, a^{*}$, and $b^{*}$ scale are listed in Table 4 . The color saturation for both colored polypropylenes was achieved at $0.1 \mathrm{wt} \%$ of the pigment, in the course of $\Delta E$ changes analysis. $\beta$-Quinacridone revealed much higher drop of the $L^{*}$ parameter which might have caused the reduction of final product transparency. This effect, depending on the application, may be either advantageous or disadvantageous. The total color difference change of $\Delta E^{*}$, observed for $\gamma$-phase quinacridone modified iPP, was more intense than for $\beta$-phase quinacridone modified iPP. In case of 
TABLE $4: L^{*}, a^{*}$, and $b^{*}$ parameters of pure iPP and iPP containing various amounts of quinacridone pigments.

\begin{tabular}{|c|c|c|c|c|c|c|c|c|}
\hline \multirow{2}{*}{$\begin{array}{l}\text { Amount of pigment } \\
\text { wt } \%\end{array}$} & \multicolumn{4}{|c|}{$\gamma$-Quinacridone (E5B) } & \multicolumn{4}{|c|}{$\beta$-Quinacridone (ER 02) } \\
\hline & $L^{*}$ & $a^{*}$ & $b^{*}$ & $\Delta E^{*}$ & $L^{*}$ & $a^{*}$ & $b^{*}$ & $\Delta E^{*}$ \\
\hline 0 (iPP) & 62.17 & 0.57 & 2.03 & - & 62.17 & 0.57 & 2.03 & - \\
\hline 0.01 & 46.79 & 30.11 & -7.31 & 34.59 & 44.52 & 18.45 & -12.21 & 28.88 \\
\hline 0.05 & 37.47 & 35.64 & 4.1 & 42.94 & 31.45 & 21.13 & -2.82 & 37.28 \\
\hline 0.1 & 35.06 & 31.16 & 9.43 & 41.54 & 29.32 & 16.44 & 2.22 & 36.48 \\
\hline 0.5 & 34.45 & 28.43 & 11.2 & 40.36 & 28.64 & 14.61 & 4.67 & 36.45 \\
\hline 1 & 35.25 & 29.22 & 11.87 & 40.53 & 28.95 & 15.29 & 5.21 & 36.47 \\
\hline 2 & 34.17 & 27.35 & 11.29 & 39.84 & 28.28 & 12.77 & 4.29 & 36.09 \\
\hline
\end{tabular}

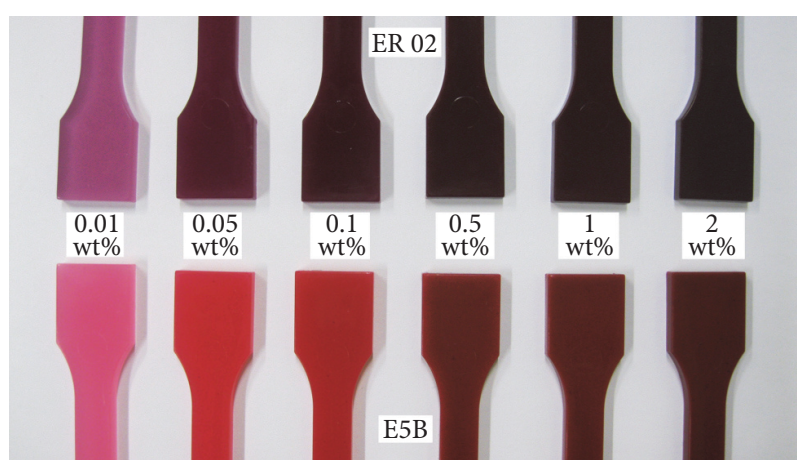

FIGURE 5: Polypropylene injection molded samples containing various quinacridone pigment amounts.

$\gamma$-quinacridone addition, $\Delta E^{*}$ parameter achieved the value of 34.59 for the lowest amount of pigment $(0.01 \mathrm{wt} \%)$. The incorporation of $\beta$-quinacridone similar concentration into iPP matrix gives $\Delta E^{*}$ parameter equal to 28.88 .

\section{Conclusions}

The incorporation of small amount of the pigment (0.01 wt\%) into semicrystalline polymeric matrix, such as isotactic polypropylene, may result in strong modification of its mechanical and thermal properties, as well as morphology. $\beta$ - and $\gamma$-quinacridone pigments showed strong nucleation efficiency during modification of iPP. The addition of both pigments led to an increase of the crystallization temperature; however, their presence in polypropylene matrix provoked different crystallization effects.

$\beta$-Quinacridone (ER-01) acted as a strong $\alpha$ nucleating agent, whereas $\gamma$-quinacridone (E5B) may be described as a low efficiency $\beta$-phase nucleating agent. Its $\beta$-nucleation ability is much smaller than the one of another $\gamma$-quinacridone grade (E3B) described in literature. Colorization ability of both quinacridone pigments considered was similar and even the smallest amount of the modifier led to strong color changes.

\section{Conflicts of Interest}

The authors declare that there is no conflict of interests regarding the publication of this paper.

\section{Acknowledgments}

The presented research results, executed under the subject of no. $02 / 25 / \mathrm{DSPB} / 4310$, were funded with grants for education allocated by the Ministry of Science and Higher Education in Poland.

\section{References}

[1] B. Lotz, J. C. Wittmann, and A. J. Lovinger, "Structure and morphology of poly(propylenes): a molecular analysis," Polymer, vol. 37, no. 22, pp. 4979-4992, 1996.

[2] B. Monasse and J. M. Haudin, "Growth transition and morphology change in polypropylene," Colloid \& Polymer Science, vol. 263, no. 10, pp. 822-831, 1985.

[3] M. Blomenhofer, S. Ganzleben, D. Hanft et al., "'Designer' nucleating agents for polypropylene," Macromolecules, vol. 38, no. 9, pp. 3688-3695, 2005.

[4] R. Pantani, I. Coccorullo, V. Speranza, and G. Titomanlio, "Modeling of morphology evolution in the injection molding process of thermoplastic polymers," Progress in Polymer Science, vol. 30, no. 12, pp. 1185-1222, 2005.

[5] J. Andrzejewski, N. Tutak, and M. Szostak, "Polypropylene composites obtained from self-reinforced hybrid fiber system," Journal of Applied Polymer Science, vol. 133, no. 15, article 43283, 2016.

[6] M. Dobrzyńska-Mizera, M. Dutkiewicz, T. Sterzyński, and M. L. Di Lorenzo, "Polypropylene-based composites containing sorbitol-based nucleating agent and siloxane-silsesquioxane resin," Journal of Applied Polymer Science, vol. 133, no. 22, Article ID 43476, 2016.

[7] M. Gahleitner, C. Grein, S. Kheirandish, and J. Wolfschwenger, "Nucleation of polypropylene homo- and copolymers," International Polymer Processing, vol. 26, no. 1, pp. 2-20, 2011.

[8] A. Brzozowska-Stanuch, S. Rabiej, J. Fabia, and J. Nowak, "Changes in thermal properties of isotactic polypropylene with different additives during aging process," Polimery/Polymers, vol. 59, no. 4, pp. 302-307, 2014.

[9] J. C. Wittmann and B. Lotz, "Epitaxial crystallization of polyethylene on organic substrates: a reappraisal of the mode of action of selected nucleating agents," Journal of Polymer Science. Part B, Polymer physics, vol. 19, no. 12, pp. 1837-1851, 1981.

[10] A. Bhatia, V. N. Jayaratne, G. P. Simon, G. H. Edward, and T. W. Turney, "Nucleation of isotactic polypropylene with metal monoglycerolates," Polymer, vol. 59, pp. 110-116, 2015. 
[11] A. Zubrowska, R. Masirek, E. Piorkowska, and L. Pietrzak, "Structure, thermal and mechanical properties of polypropylene composites with nano- and micro-diamonds," Polimery/ Polymers, vol. 60, no. 5, pp. 331-336, 2015.

[12] J. Varga, "Supermolecular structure of isotactic polypropylene," Journal of Materials Science, vol. 27, no. 10, pp. 2557-2579, 1992.

[13] D. Hybiak and J. Garbarczyk, "Silver nanoparticles in isotactic polypropylene (iPP) Part I. Silver nanoparticles as metallic nucleating agents for $\beta$-iPP polymorph," Polimery, vol. 59, no. 7-8, pp. 585-591, 2014.

[14] D. Hybiak, S. Chmielewska, and J. Garbarczyk, "Silver nanoparticles in isotactic polypropylene. Part II. Molecular modelling of polypropylene chains arrangement on the surface of silver nanoparticles," Polimery/Polymers, vol. 60 , no. 11-12, pp. 700704, 2015.

[15] X. Li, C. Guo, Y. Zhang, K. Liu, and J. Zhang, “The Morphology and mechanical properties of isotactic polypropylene injectionmolded samples with the presence of $\beta$-nucleation agent and periodical shear field," Journal of Macromolecular Science, Part B: Physics, vol. 54, no. 2, pp. 215-229, 2015.

[16] M. L. Cerrada, E. Pérez, R. Benavente, J. Ressia, C. Sarmoria, and E. M. Vallés, "Gamma polymorph and branching formation as inductors of resistance to electron beam irradiation in metallocene isotactic polypropylene," Polymer Degradation and Stability, vol. 95, no. 4, pp. 462-469, 2010.

[17] H. Palza, J. M. López-Majada, R. Quijada et al., "Comonomer length influence on the structure and mechanical response of metallocenic polypropylenic materials," Macromolecular Chemistry and Physics, vol. 209, no. 21, pp. 2259-2267, 2008.

[18] E. Bociąga and M. Trzaskalska, "Influence of ageing on the gloss, color, and structure of colored ABS," Color Research and Application, vol. 41, no. 4, pp. 392-398, 2016.

[19] T. Sterzyński, P. Calo, M. Lambla, and M. Thomas, "Trans- and Dimethyl quinacridone nucleation of isotactic polypropylene," Polymer Engineering and Science, vol. 37, no. 12, pp. 1917-1927, 1997.

[20] A. Gradys, P. Sajkiewicz, A. A. Minakov et al., "Crystallization of polypropylene at various cooling rates," Materials Science and Engineering A, vol. 413-414, pp. 442-446, 2005.

[21] J. Broda, A. Gawlowski, C. Slusarczyk, A. Wlochowicz, and J. Fabia, "The influence of additives on the structure of polypropylene fibres," Dyes and Pigments, vol. 74, no. 3, pp. 508-511, 2007.

[22] M. Huang, X. Li, and B. Fang, " $\beta$-nucleators and $\beta$-crystalline form of isotactic polypropylene," Journal of Applied Polymer Science, vol. 56, no. 10, pp. 1323-1337, 1995.

[23] E. F. Paulus, F. J. J. Leusen, and M. U. Schmidt, "Crystal structures of quinacridones," CrystEngComm, vol. 9, no. 2, pp. 131143, 2007.

[24] G. Lincke, "A review of thirty years of research on quinacridones. X-ray crystallography and crystal engineering," Dyes and Pigments, vol. 44, no. 2, pp. 101-122, 2000.

[25] J. Broda, "Polymorphic composition of colored polypropylene fibers," Crystal Growth and Design, vol. 4, no. 6, pp. 1277-1282, 2004.

[26] M. Barczewski, M. Dobrzyńska-Mizera, M. Dutkiewicz, and M. Szołyga, "Novel polypropylene $\beta$-nucleating agent with polyhedral oligomeric silsesquioxane core: synthesis and application," Polymer International, vol. 65, no. 9, pp. 1080-1088, 2016.

[27] A. T. Jones, J. M. Aizlewood, and D. R. Beckett, "Crystalline forms of isotactic polypropylene," Die Makromolekulare Chemie, vol. 75, no. 1, pp. 134-158, 1964.
[28] Q. Dou, "Effect of calcium salts of glutaric acid and pimelic acid on the formation of $\beta$ crystalline form in isotactic polypropylene," Polymer - Plastics Technology and Engineering, vol. 47, no. 9, pp. 851-857, 2008

[29] A. Romankiewicz, T. Sterzyński, and W. Brostow, "Structural characterization of $\alpha$ - and $\beta$-nucleated isotactic polypropylene," Polymer International, vol. 53, no. 12, pp. 2086-2091, 2004.

[30] J. Broda, "WAXS investigations of mass-coloured polypropylene fibres," Fibres and Textiles in Eastern Europe, vol. 11, no. 5, pp. 115-119, 2003.

[31] The International Commission on Illumination ICO, "Recommendations on uniform color spaces, color-difference equations, psychometric color terms," CIE, 1978.

[32] X. Zhao, Y. Zhang, Y. Huang, H. Gong, and J. Zhao, "Synthesis and characterization of neodymium doped yttrium molybdate high NIR reflective nano pigments," Dyes and Pigments, vol. 116, pp. 119-123, 2015.

[33] W. Brostow, H. E. Hagg Lobland, and S. Khoja, "Brittleness and toughness of polymers and other materials," Materials Letters, vol. 159, pp. 478-480, 2015.

[34] C. Grein, K. Bernreitner, and M. Gahleitner, "Potential and limits of dynamic mechanical analysis as a tool for fracture resistance evaluation of isotactic polypropylenes and their polyolefin blends," Journal of Applied Polymer Science, vol. 93, no. 4, pp. 1854-1867, 2004. 

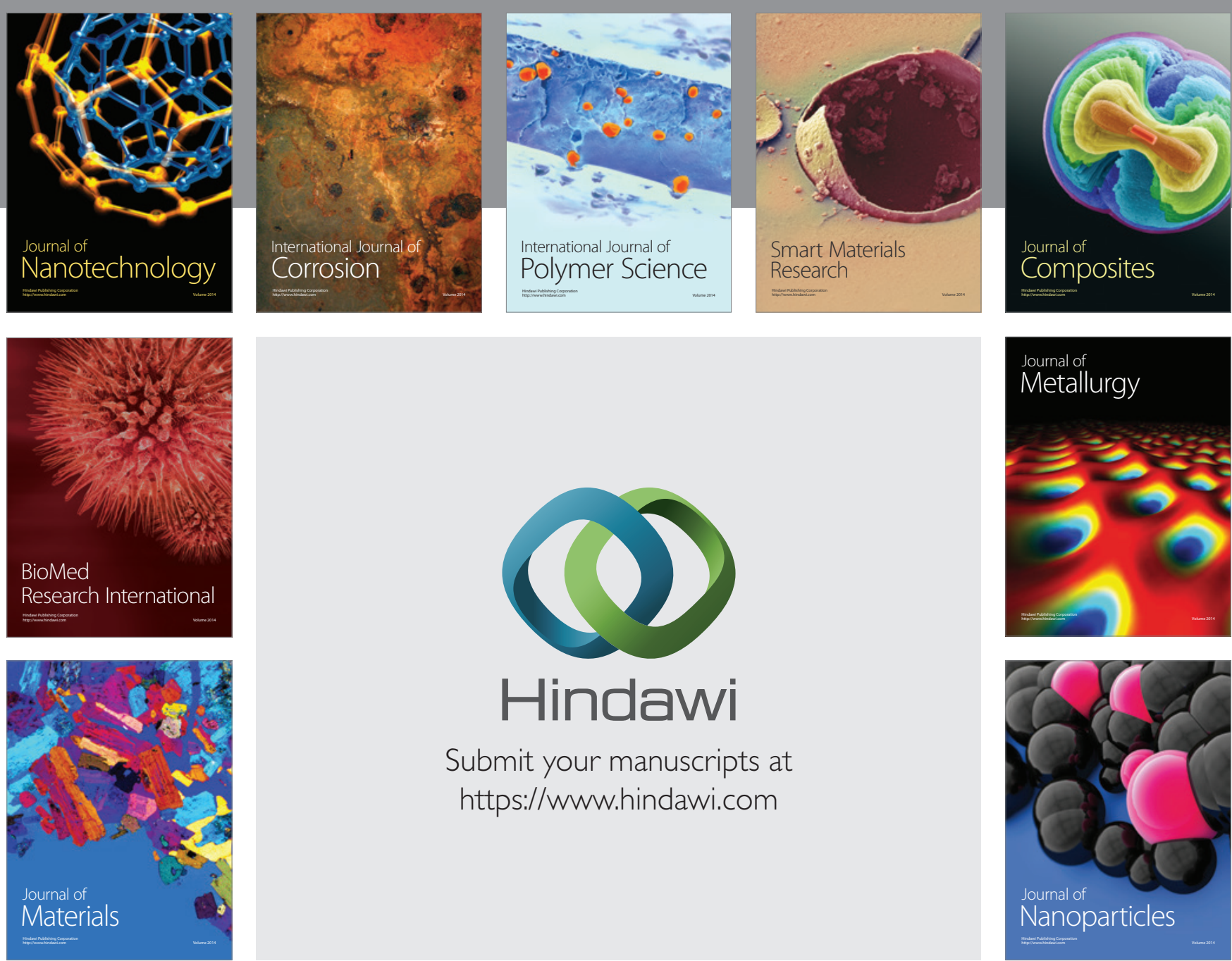

\section{Hindawi}

Submit your manuscripts at

https://www.hindawi.com

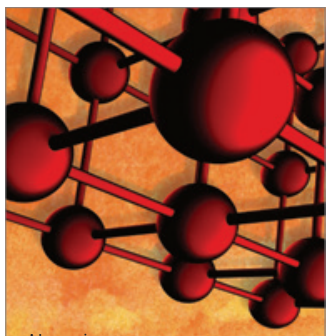

Materials Science and Engineering
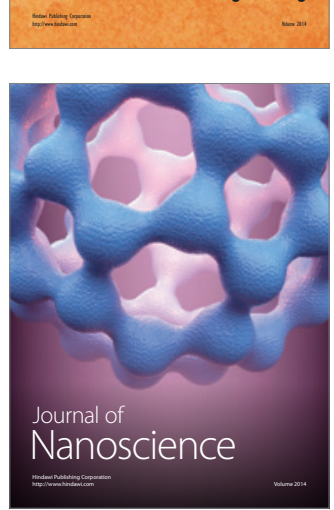
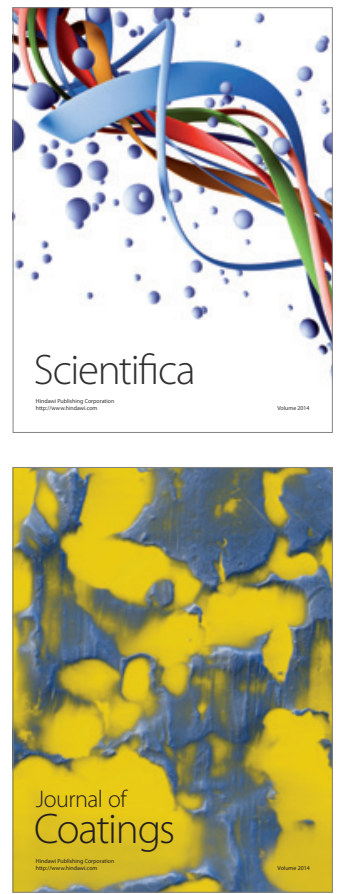
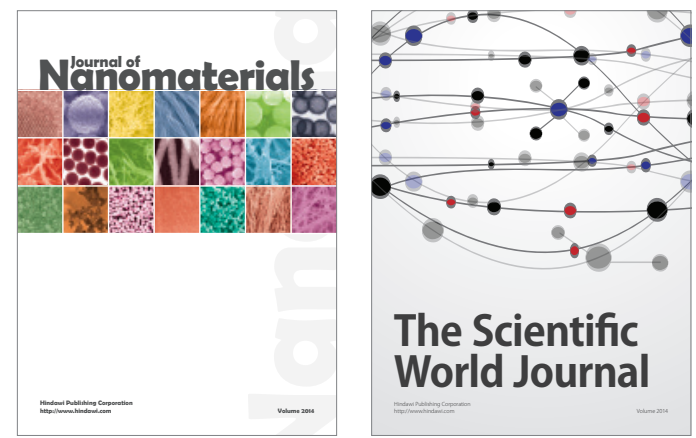

The Scientific World Journal
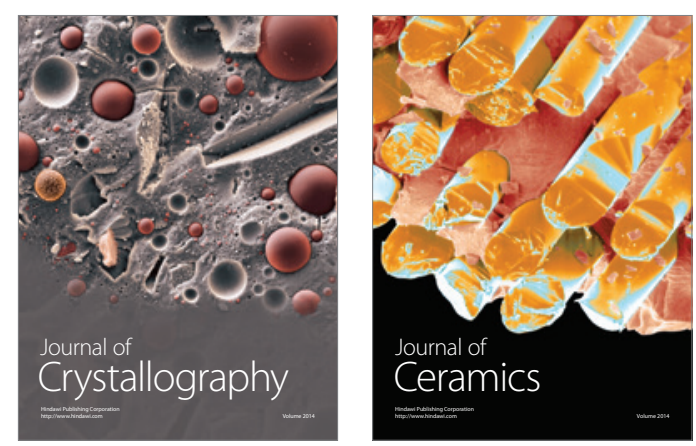
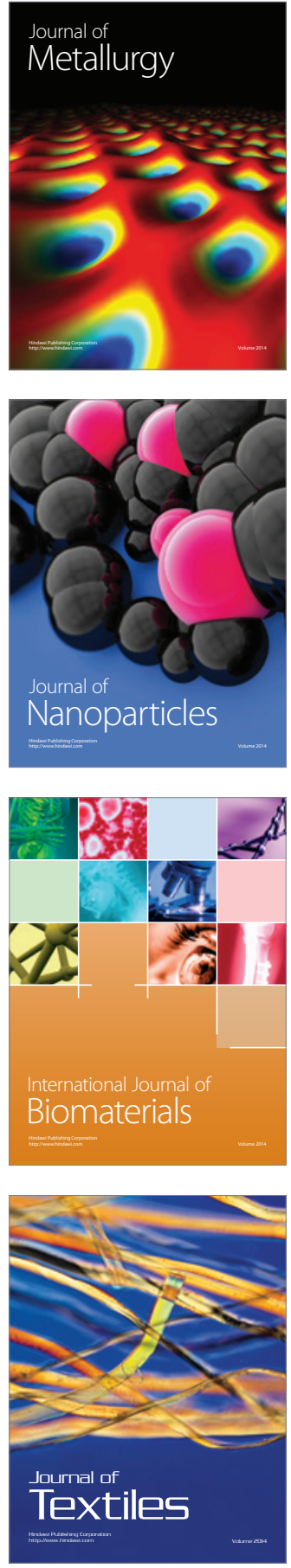